\title{
Introduction: Motivations for Relativism
}

\section{Max Kölbel}

The truth of an utterance depends on various factors. Usually these factors are assumed to be: the meaning of the sentence uttered, the context in which the utterance was made, and the way things are in the world. Recently, however, a number of cases have been discussed where there seems to be reason to think that the truth of an utterance is not yet fully determined by these three factors, and that truth must therefore depend on a further factor. The most prominent examples include utterances about values, utterances attributing knowledge, utterances that state that something is probable or epistemically possible and utterances about the contingent future. In these cases, some have argued, the standard picture needs to be modified to admit extra truth-determining factors, and there is further controversy about the exact role of any such extra factors. All the essays in this volume are about this issue. It is a narrowly defined issue in the philosophy of language, but one with important connections to other areas of philosophy, such as meta-ethics, metaphysics and epistemology.

In this introductory essay, I shall attempt to provide a systematic overview. I shall outline the standard approach to semantics, modifications of which have been demanded. I then look at one of the cases, matters of taste, and examine in some detail what the motivations for modifying standard semantics are. I shall then outline the parallel reasoning in a series of other cases. Finally, I shall give a brief summary of the contributions to this volume. 


\section{A Starting Point}

There is a picture of natural language meaning that is familiar from the likes of Frege, Carnap, Searle, Kaplan, Lewis, Stalnaker and many others. In this picture, propositions take centre stage. Propositions are the objects of belief, assertion, supposition, etc, and it is the expression of propositions (be it assertorically or otherwise) that linguistic communication revolves around. In central cases of communication, a speaker utters an assertoric sentence and thereby expresses a proposition. This proposition may or may not be something this speaker believes, and may or may not be something the audience comes to believe. Though in some sense perhaps believing what one asserts and believing what others assert is the paradigm of smooth communication.

Propositions are not only the objects of thought and speech, they are also truthbearers, and it is often thought that propositions are absolute truth-bearers in the sense that a proposition by itself determines a truth-value, or at least a truth-value given the way the world is. Frege seems to be the main source for this view. In "The Thought", for example, he concludes that sentences containing indexical expressions like "yesterday" are "not the complete expression of a thought". ${ }^{1}$ He concludes this from the fact that the very same sentence can be true at one time and not true at another. This marks the birth of the modern theory of indexicals: the meaning of a sentence does not associate the sentence directly with a proposition. Rather, the sentence's meaning provides a rule or function that takes one from a context of use to a proposition. Thus, if the sentence "Yesterday was Sunday." is used, it will express a proposition concerning the day before the day on which the utterance takes place. Frege's argument is an early example of what

${ }^{1}$ Cf. Frege 1918, p. 64. For some more of Frege's reflections on the absoluteness of truth, see 1918, pp. 689 and [1915], p. 271. 
has recently been called a "context-shifting argument" (Cappelen \& Lepore 2004), i.e. an argument that begins from the premiss that two utterances of the same sentence differ in truth-value when uttered in contexts that differ in certain respects, and concludes that the sentence must be context-sensitive in such a way that the proposition it expresses depends systematically on those aspects of the context. The aspects of the context on which context-sensitivity can turn can of course include the speaker of the context, the audience, its location, etc. ( "my uncle", "you", "over here" etc.).

The basic model according to which a sentence's meaning together with the context determines the proposition expressed is more or less accepted my most theorists. ${ }^{2}$ However, not everyone has always agreed with the Fregean assumption that propositions have their (actual) truth-values absolutely. Most notably Prior (1967) and Kaplan (1977) have allowed tensed propositions, i.e. propositions whose truth-value varies with time. Thus, the sentence "It is Monday." can be seen to express the same, tensed proposition, whenever it is used. This proposition is true on Mondays only, and false on other days. Others have toyed with the idea of otherwise perspectival propositions, such as the proposition that one's own pants are on fire, as opposed to the proposition that some particular person's pants are on fire ${ }^{3}$

\footnotetext{
${ }^{2}$ There is considerable controversy about extent to which the conventional meaning of a natural language sentence consists in a specifiable rule that takes one from context to propositional content. "Contextualists" stress the pragmatic nature of this, which may involve processes of "free enrichment" (Travis 1997, Wilson and Sperber 2001, Carston 2002, Recanati 2004), while more traditional semanticists (Kaplan 1977, Lewis 1980, Stanley 2001, Borg 2004, Lepore \& Cappelen 2004, Predelli 2005) insist that the semantic content of an utterance is determined merely by a conventional semantic rule and the context of use.

3 For example, Lewis 1979a and Perry 1979. Tensed propositions seem now to be out of fashion-a different, quantificational treatment of the tenses has become more customary, apparently without any conclusive reason for this development (see King 2003). Perspectival propositions, on the other hand, are
} 
Traditionally, then, the truth-value of a proposition has been thought to be relative to a possibly world only, and there has been dissent from some quarters who think truth should be further relativized to times and agents. In this volume a number of new proposals of relativizations are under discussion. Thus, some argue that the truth of utterances of sentences like "Matisse is better than Picasso." depends on a standard of taste. Others argue that the truth of utterances of sentences like "Anna knows she has hands." depends on practical interests; and that the truth of utterances of "Greece might win the world cup.” depends on a state of knowledge.

Suppose we want to say that the truth-value of utterances of the sentence "Matisse is better than Picasso." varies with a standard of taste. We shall review reasons for this type of claim in more detail later on, but suppose our reason is that we have noticed that the correctness of an utterance of the sentence depends on the standard of taste of the utterer, and we are convinced that this is to do with a variation in the truth-value of the utterances in question (and not a variation in some other value, such as conversational appropriateness, sincerity etc.). There are two basic ways of construing the dependence, a more standard way and a more innovative way.

First, it may be a case of ordinary context-sensitivity or indexicality. Two utterances of "Yesterday was Sunday." will express different propositions if they are made on different days, and as a consequence they can vary in truth value. Similarly, two utterances of "Matisse is better than Picasso.", on this more standard view, will express different propositions if they are made in suitably different contexts, and this difference

alive and well, in the guise of propositions that are identical to sets of "centred possible worlds" (see for example Chalmers 2002 and Stalnaker 2001). 
in proposition expressed can account for the observed difference in truth-value. One way of implementing this proposal would be to say that the utterer's standard of taste, or preferences, are the contextual factor in question. Thus, on this proposal, the sentence "Matisse is better than Picasso." would exhibit the same sort of context-sensitivity as the sentence "According to standards of taste like my own, Matisse is better than Picasso.". Both sentences will express different propositions in the mouths of suitably different speakers.

Secondly, the dependence of the truth of utterances of the sentence on a standard of taste could be construed in analogy with tensed propositions. On a temporalist view, the sentence "MK is hungry." expresses the same proposition whenever it is used. However, the truth-value of that proposition varies with time: on most days it is true before lunch and (fortunately) not true after lunch. Similarly, on the second proposal, the sentence "Matisse is better than Picasso." expresses the same proposition whenever used, but that proposition varies in truth-value with a standard of taste, so that the proposition can be true relative to one standard of taste and false relative to another. Just like temporalism, this view will need to spell out further under what conditions uttering this sentence counts as correct - the envisaged motivating datum was that the correctness of an utterance of the sentence depended on the utterer's standard of taste. One possible answer would follow the paradigm of temporalism and construe the truth of an utterance as the truth of the proposition expressed relative to the standard of taste of the person who made the utterance. Another, apparently more radical answer would maintain that even the truth of utterances remains relative to a standard of taste. I shall return to this difference. 
Let me summarize briefly. The most familiar picture of linguistic meaning has it that the meaning of a sentence centrally consists in a rule or function that determines the content or proposition the sentence would express for each context in which the sentence may be used. This proposition in turn determines a truth-value for each way the world may happen to be (each possible world), and in particular it determines a truth-value given the way the world actually is. An older challenge to the traditional picture concerns whether the truth-values of propositions depend on a time or an agent. The focus of this book is whether there are novel truth-determining factors, such as standards of taste and states of knowledge, and how exactly such a determination relation should be construed. The two basic rival options were as follows. First, the view that the sentences in question merely exhibited a hitherto unnoticed contextual dependence analogous to indexicality: the same sentence expresses different standard propositions in different contexts. Secondly the view that the sentences in question express non-standard propositions that exhibit a relativity of truth analogous to that postulated, for example, by temporalists: the sentences in question express non-standard propositions whose truth-values are relative to an extra factor.

I shall call views of the second kind "relativist". Relativism is therefore the view that some propositions vary in their truth-value with some parameter(s) over and above the possible world parameter. ${ }^{4}$

\footnotetext{
${ }^{4}$ My definition of "relativism" is thus fairly wide and differs from MacFarlane's. MacFarlane wants to reserve the label "relativist" for those who claim that the truth of utterances is relative (2005, p. 325). Saying that propositions vary in truth-value with a non-standard parameter is not sufficient for relativism in MacFarlane's sense, for even with non-standardly relativized propositions one can still define utterance truth in such a way as to be absolute (this corresponds to the first of the two possible answers mentioned two paragraphs back).
} 


\section{Standard Semantics}

In order to examine how any of these relativizations can be motivated, I propose to look at the foundations of natural language semantics in a little more detail. I shall begin by looking at the form of semantic theories, and the role of truth-predicates in them. It will turn out that semantic theories for natural languages define a three-place truth-predicate applicable to sentences, and that some extra-semantic principles are needed in order to relate this semantic truth-predicate to truth in any pre-theoretic sense.

We can provide a semantics for a formal language by assigning semantic values, or extensions to the basic expressions of that language together with some rules as to how the semantic values of complex expressions are determined by those of the basic expressions from which they are built up. In the case of sentences (one kind of expression), the semantic values are truth-values. Given that a language consists of a body of sentences, a semantics for that language can take the form of a recursive definition of a one-place truth-predicate $\mathrm{T}(s)$ ranging over the sentences $s$ of the language in question.

In extending this approach to natural languages, the assignment of semantic values is initially complicated by two fundamental problems: non-extensional phenomena and context-sensitivity. ${ }^{5}$ Let us look at each of these in turn.

First, natural languages contain complex expressions whose extension is not fully determined by the extensions of its component expressions. For example, the extensions (truth-values) of "Joe believes that Hesperus is Phosphorus" and of "Bush might not have won the election." seem to depend not just on the extensions of the component words.

\footnotetext{
${ }^{5}$ There will of course be further and detailed problems, for example problems of formalization.
} 
The standard solution originates with Carnap (1947): we take expressions to have their extensions not absolutely but relative to possible worlds. In other words, expressions have intensions, and for each possible world an intension determines an extension. This allows one to treat non-extensional contexts as intensional operators. For example, we can say that the sentence resulting from prefixing a sentence $s$ with the operator "possibly" is true at a possible world just if there is a possible world (accessible from it) at which $s$ is true. The familiar semantic clause runs something like

(Poss) For all $s, w$ :

$\mathrm{T}($ "Possibly" $s, w)$ iff there is a $w^{*}$ accessible from $w$ such that $\mathrm{T}\left(s, w^{*}\right){ }^{6}$

Similarly, we can say that the result of prefixing a sentence $s$ with "Joe believes that" is true at a world just if $s$ is true at all possible worlds that Joe does not rule out at that world. $^{7}$ Whatever the details, the semantics now defines not a one-place truth predicate $\mathrm{T}(s)$, but a two-place truth predicate $\mathrm{T}(s, w)$ relating sentences to the possible worlds at which they are true.

Secondly, semantic theories for natural languages need to make room for contextsensitive expressions or indexicals. Some expressions do not have the same extension whenever they are used. For example, the very same expression "my uncle" will have a certain extension if used by me and a different extension if used by you (except if you are my sibling). Thus, it seems that extensions also depend on the context of use. This motivates adding an argument place to the sentential truth predicate: sentences are true relative to contexts of utterance.

\footnotetext{
6 " $\wedge$ " is a concatenation sign in the meta-language.

${ }^{7}$ For one account along these lines, see Stalnaker 1987.
} 
For reasons explained by Kaplan (1977, pp. 507-10), these two relativizations of the sentential truth predicate - to a possible world and to a context of use - must be treated as separate. We need "double-indexing". The reason, briefly, is that we want to distinguish between necessity (truth at all possible worlds) and logical truth (truth at all contexts of utterance). As a result, a standard semantic theory for a natural language will define not a two-place, but a three-place predicate $\mathrm{T}(s, c, w)$, relating a sentence with a context in which it may be used and a possible world. This is called a "double-index semantics".

In the previous section, I have already introduced one very familiar way of thinking about double-indexing, which involves portraying it as a two-stage process, in which a sentence in a context of use determines a proposition, and a proposition in a possible world determines a truth-value. The best-known exposition of this type of approach is probably Kaplan's “On Demonstratives” (but see also Lewis 1980). Kaplan thinks of a semantic theory as assigning to each expression a character, where a character is just a function from contexts of use as arguments to contents (i.e. intensions) as values. Contents in turn are functions which take circumstances of evaluation as argument and have extensions as values. On the standard picture, circumstances of evaluation are merely possible worlds. However, as we shall see, some theorists, including Kaplan himself, add further factors to the circumstances, such as a time or a person.

There are different ways of construing contexts of use. Some think of a context of use as an $n$-tuple $<a, l, t, w, \ldots>$ of an agent, a location, a time, a possible world etc (e.g. Kaplan 1977, Predelli 2005). Others construe contexts of use as a concrete situation in which a sentence is - or can be-uttered (Lewis 1980). But a context does a certain job in 
the semantics, and it has to be rich enough to do that job. A context's job will be to determine for each indexical the intension that indexical has with respect to that context. If the semantics is for a natural language like English, then each context must at least determine a speaker, a location, a time, a world, etc, because of indexicals like "I", "here", "now", "actual". Thus, in whichever way we construe contexts, we must be able to make sense of the idea of the speaker, location, time, world etc determined by a context (or the speaker, location, time etc of a context). ${ }^{8}$

A standard semantics will define the sentential truth-predicate $\operatorname{True}(s, c, w)$ indirectly via a another, more basic semantic value, namely the truth, or satisfaction, of a formula at a context, at a world and with respect to an assignment of values to the individual variables $(\operatorname{Sat}(s, c, w, a))$. This is required for a compositional treatment of the quantifiers. I will ignore this complication in what follows and concentrate on closed sentences.

The job of a standard semantic theory, then, is to deliver a definition of a threeplace sentential truth-predicate $\operatorname{True}(s, c, w)$. The definition will be recursive and involve compositional clauses like (Poss) above. ${ }^{9}$ Such a theory is, however, a purely abstract theory, that does not, by itself have any observable consequences. This would be so even if the sentences for which we are defining $\operatorname{True}(s, c, w)$ were exactly the sentences (or phonetic types) of the English language. That this is so becomes clear if one considers the

\footnotetext{
${ }^{8}$ On the $n$-tuple approach to context, it makes sense to restrict the set of contexts $\langle a, l, t, w, \ldots>$ to those where $a$ is located in $l$ at $t$ and at $w$.

${ }^{9}$ The compositional clauses for "Possibly" will normally concern formulae in general, so (Poss) is only a special case of the sort of compositional clause one would find regarding a possibility operator in a semantic theory.
} 
fact that we have no pre-theoretical data concerning a three-place sentential truthpredicate that relates sentences with contexts and possible worlds. Such a predicate is a technical term introduced by semanticists to express a theoretical notion. Pre-theoretical observations are of a different kind. In general, they are data concerning the correct use of language. ${ }^{10}$ They might be data concerning the conditions under which utterances are correct, perhaps in various different respects, or which utterances say something true. Or they might be data concerning which sentences are synonymous, or utterances of which sentences are incompatible with the utterance of which other sentence. So what, then, are the testable predictions that a semantic theory for a natural language makes?

Semanticists regularly, and often silently, assume a principle of application that relates the claims made in a theory of semantic content for a natural language to pretheoretical claims about that language. ${ }^{11}$ One simple such principle is that adopted by Kaplan when he defines a notion of truth for "occurrences" of sentences, which is supposed to correspond to a pre-theoretical notion of truth we have for occurrences or utterances of sentences. On Kaplan's definition, an occurrence of a sentence in a context is true just if the proposition expressed by the sentence in that context is true with respect

\footnotetext{
${ }^{10}$ Some purists (e.g. some corpus linguists) might say that all we can observe is the time and place at which tokens of sentences are produced, not the correctness of such performances. However, natural language semanticists usually operate with data concerning which utterances (real or imagined) are correct, felicitous or true. I am assuming that this practice is legitimate because (a) semantics models competence, i.e. correct usage, not actual performance and (b) ordinary competent speakers' judgements are a good indicators (ceteris paribus) as to which utterances under what conditions are correct or true.

${ }^{11}$ I myself have been making such an assumption in my exposition so far, for example when explaining why semantic theories for natural languages should be double-indexed. For a sophisticated discussion of the relationship between semantics and language use see Predelli 2005.
} 
to the possible world of that context. ${ }^{12}$ In other words, an occurrence of a sentence in a context is true just if the sentence is true (in the sense defined by the semantics) in the context of use of that occurrence and at the world of that occurrence:

(P) $\quad$ For all sentences $s$ and contexts $c$ : an occurrence of $s$ in $c$ is true just if $\mathrm{T}(s, c, \mathrm{~W}(c))$. (where $\mathrm{W}(c)$ is the world of $c$ )

Given such a bridging principle, we can use what the semantics says about the truth of sentences relative to contexts and worlds to generate predictions as to which occurrences will be true under what kinds of condition.

To give a concrete example, let's consider a semantics that delivers a clause like this:

(1) For all $c, w$ : T("I am hungry.", $c, w)$ iff in $w$ the speaker of $c$ is hungry at the time of $c$.

In what sense, if any, would clause (1) be intuitively correct? Once we assume (P), we can generate predictions as to the truth of particular utterances of the sentence. For example, let's consider two utterances of the sentence, both by Oscar, one at noon, one at $2 \mathrm{pm}$. Suppose Oscar is hungry at noon but not hungry at $2 \mathrm{pm}$. Then intuitively, we would say that the first utterance is true, while the second utterance is not. This intuitive result is also predicted by the semantics and $(\mathrm{P})$, for from the assumptions we made:

(a) $\quad u$ is an occurrence of "I am hungry" in a context $c 1$.

(b) $\quad v$ is an occurrence of "I am hungry" in a context $c 2$.

(c) $\mathrm{S}(c 1)=\mathrm{S}(c 2)=$ Oscar, $\mathrm{T}(c 1)=12$ noon, $\mathrm{T}(c 2)=2 \mathrm{pm}$.

${ }^{12}$ Cf. Kaplan 1989, p. 522. Similar definitions of truth for utterances or tokens are offered by Lewis 1975 , p. 172, and Chalmers (forthcoming, principle (T3)). This principle is discussed in detail under the label "the Classic Reduction" by Predelli and Stojanovic in their contribution to this volume. 
(d) Oscar is hungry at 12 noon. Oscar is not hungry at $2 \mathrm{pm}$.

we can generate the prediction that $u$ is true and $v$ is not. ${ }^{13}$ To the extent to which the theory's predictions conform to the intuitive judgements as to the truth of utterances, the theory is confirmed. Without some bridging principle like $(\mathrm{P})$, a semantic theory is not an empirically testable hypothesis, and any impression that some formal semantics for a natural language is intuitively correct will rely on the assumption of some such principle.

Evidently, application principle $(\mathrm{P})$ represents a considerable simplification. To begin with, we don't ordinarily call utterances or occurrences of sentences true. When we do apply some notion of truth to utterances or occurrences of sentences, then it is usually in an at least semi-technical context. ${ }^{14}$ In ordinary, non-theoretical contexts, we might make judgements about whether for example what someone said, asserted, claimed, believed or supposed is true. Our intuitive judgements about truth therefore seem to be about the truth of the objects of assertion, belief, etc., i.e. of propositions. Another difficulty is that linguistic utterances can convey a host of different propositions, each of them triggering intuitions as to truth. For example, a hyperbolic utterance of "I could eat an ox." might carry a false literal content and a true communicated content. Which of these is relevant to adjudicating the output of a semantic theory?

\footnotetext{
${ }^{13}\left(1^{*}\right) \quad \forall w$ [True(“I am hungry.", $\left.c 1, w\right)$ iff in $w \mathrm{~S}(c 1)$ is hungry at $\left.\mathrm{T}(c 1)\right] \quad$ instance of (1)

(1**) $\quad \forall w$ [True("I am hungry.", $c 2, w)$ iff in $w \mathrm{~S}(c 2)$ is hungry at $\mathrm{T}(c 2)] \quad$ instance of (1)

(c*) $\quad \forall w$ [True("I am hungry.", $c 1, w)$ iff in $w$ Oscar is hungry at 12 noon] from (1*) and (c)

(c**) $\quad \forall w$ [True("I am hungry.", $c 2, w)$ iff in $w$ Oscar is hungry at $2 \mathrm{pm}] \quad$ from (1**) and (c)

$\left(\mathrm{P}^{*}\right) \quad u$ is correct iff Oscar is hungry at 12 noon in $\mathrm{W}(c 1) . \quad$ From (c*), (a) and (P)

$\left(\mathrm{P}^{* *}\right) \quad v$ is correct iff Oscar is hungry at $2 \mathrm{pm}$ in $\mathrm{W}(c 2) . \quad$ From (c**), (b) and (P)
}

The result that $u$ is correct and $v$ is not now follows from $(\mathrm{d}),\left(\mathrm{P}^{*}\right)$ and $\left(\mathrm{P}^{* *}\right)$.

${ }^{14} \mathrm{Cf} . \S 7$ of MacFarlane (this volume). 
One response to this sort of difficulty would be properly to take into account the illocutionary aspects of natural language. In addition to the contents or propositions that sentences express in contexts of use, sentences also have illocutionary force markers, i.e. they can be declarative, interrogative or imperative. When a natural language sentence is uttered, a proposition is not just "expressed", it is also, for example, asserted. If we add a theory of illocutionary force to a pure semantics of the sort already described, we get predictions of the form: the utterance of $s$ in $c$ is an assertion that $p$. Or: the utterance of $s$ in $c$ is a request that $p .{ }^{15}$ If we have a pre-theoretical grasp of asserting and requesting, we would then be in a position to confirm or disconfirm the combination of the semantics with the modified application principle.

In my view, this is the most promising approach to natural language semantics. However, it would lead us too far astray if we entered a detailed discussion of assertion and other illocutionary acts at this point. Fortunately, a shortcut is available. We are currently interested in a debate about whether truth as it occurs in semantics ought to be relativized to a novel parameter, and if so, how exactly this relativization should be implemented. For these purposes, it will be sufficient to concentrate on assertoric utterances only, and on the normative role of truth in theories of assertion.

\footnotetext{
${ }^{15}$ A new application principle might look like this:

$\left(\mathrm{P}^{*}\right) \quad$ An utterance of a sentence $s$ in context $c$ is an assertion that $p$ if

(i) $\quad s$ is assertoric (and $c$ meets certain normality conditions)

(ii) For all $w$ : $\mathrm{T}(s, c, w)$ iff $p$ is true in $w$.
}

The general approach corresponds to that outlined in McDowell 1980. McDowell envisages a reductive account of assertion which will enable us to test the bipartite theory, consisting of a semantics and a theory of illocutionary force, against a general psychological theory. No such psychological reduction of assertion and of other propositional acts is in sight. However, I believe an account of assertion and other illocutionary acts that identifies the norms characteristically associated with each act type can fill this gap. 
Any theory of assertion is committed to the view that truth is in some sense a norm for assertion. It is relatively uncontroversial to say that the norms of assertion require asserters to assert only true propositions. Different theorists of assertion might have different views of the status of this requirement, some may say that it is merely a derived norm, others that it is central or basic. For example, some may think that this norm derives from a basic assertoric norm that requires sincerity ("Assert only what you believe!") and a general norm requiring the truth of beliefs ("Believe only what is true!"). However, most will agree that it is $a$ norm in the sense that if a proposition lacks truth then the norms of assertion require in some sense that it not be asserted (even though, of course, there are also other requirements which may override this requirement). We can articulate the norm as follows:

(A1) An assertion of a proposition $p$ in a context $c$ is correct (violates no norms of assertion) only if $p$ is true in the possible world of $c$.

The idea is that, given the norm requires avoidance of untrue assertions, an assertion is correct or fault free (in the sense of violating no norms at all) only if the proposition asserted is true. Assuming that an utterance of a sentence $s$ in a context $c$ expresses the proposition that is true in exactly the worlds $w$ in which $\mathrm{T}(s, c, w)$, and also restricting ourselves to assertoric, literal utterances, we thus get a principle that resembles the leftto-right direction of $(\mathrm{P})$ :

(A2) For all sentences $s$ and contexts $c$ : an utterance of $s$ in $c$ is correct only if $\mathrm{T}(s, c, \mathrm{~W}(c))$. (where $\mathrm{W}(c)$ is the world of $c$ ) 
In other words, as long as we are speaking about assertoric utterances only, an utterance of a sentence violates no norms only if the sentence is true relative to the context in which the utterance was made and to the world in which the utterance was made.

(A2) avoids some of the more obvious difficulties with the very simple principle (P) familiar from Kaplan and others. However, it is still sufficiently strong to allow intuitions about the correctness of utterances to constrain semantic theorizing somewhat. In particular, it is strong enough to serve the purposes of those who wish to argue that standard semantics is in need of modification (as we shall see in a moment).

\section{Hidden indexicals in sentences expressing judgements of taste}

(A2) has the following useful consequence: suppose there is one (literal, assertoric) utterance of a sentence $s$ and another (literal, assertoric) utterance of that sentence's negation not-s. Suppose further that the contexts in which these utterances are made are similar in all the respects that matter for the assignments of content to any indexicals contained in $s$. Then we can conclude that at most one of the utterances is free from faults. The reasoning is as follows: given that the contexts are similar in any relevant respects, and given that one of the sentences uttered is the negation of the other, the two utterances must express contradictory propositions. Thus any world in which the proposition expressed by the first utterance is true is a world in which the proposition expressed by the second is not true, and vice versa. So, if one utterance is an assertion of a true proposition, the other is an assertion of an untrue proposition. Thus, we can infer (iii) from (i) and (ii):

(i) $\quad u$ is an utterance of $s$ in $\mathrm{C} 1, v$ is an utterance of not-s in $\mathrm{C} 2$.

(ii) $\quad s$ expresses the same proposition in $\mathrm{C} 1$ and $\mathrm{C} 2$. 
(iii) $\quad u$ and $v$ are not both fault free. ${ }^{16}$

By contraposition, if two utterances of contradicting sentences $s$ and not-s are both fault free, then the contexts $\mathrm{C} 1$ and $\mathrm{C} 2$ in which the utterance were made must be relevantly different, i.e. different in such a way that $s$ would express different propositions in $\mathrm{C} 1$ and $\mathrm{C} 2 .{ }^{17}$

The contrapositive principle can be applied in the following case. Suppose Anna asserts that Depp is more handsome than Pitt and Barbara asserts that he is not. Intuitively, I believe, many would be inclined to say that under certain conditions it is possible that neither Anna not Barbara has committed any fault. These conditions might include that Anna and Barbara both believe what they say, and they believe so for good reasons. Now, let's imagine exactly such a case and consider the following two utterances:

(1a) Anna (in C1): "Depp is more handsome than Pitt."

(1b) Barbara (in C2): "Depp is not more handsome than Pitt."

Now, if we want to maintain (and ex hypothesi we do) that neither Anna nor Barbara is at fault, we must conclude that the contexts $\mathrm{C} 1$ and $\mathrm{C} 2$ in which utterances (1a) and (1b) are made are relevantly dissimilar. And "relevantly dissimilar" here means: the sentence

\footnotetext{
${ }^{16}$ For a more careful exposition of this type of argument, and one that is more sensitive to the position of intuitionists, see my 2003.

${ }^{17}$ This pattern of argument has certain similarities with what Cappelen and Lepore 2004 call "contextshifting arguments". Context shifting arguments start from a premiss that says that two utterances of the same sentence have opposing truth-values, and conclude (via a principle like $(\mathrm{P})$ ), that the sentence must be context-sensitive and for that reason express different contents in the two utterances. The style of argument here discussed is more powerful because (a) it does not need to rely on a simplification like (P), and (b) its starting premiss claims an absence of norm violations, i.e. a kind of claim that is less liable to reinterpretation.
} 
"Depp is more handsome than Pitt." contains an indexical element which is sensitive to a feature of context with respect to which $\mathrm{C} 1$ and $\mathrm{C} 2$ differ. In other words, standard semantics forces us to conclude that the sentence "Depp is more handsome than Pitt." expresses different propositions in $\mathrm{C} 1$ and $\mathrm{C} 2 .{ }^{18}$ Consequently, (1a) and (1b) do not express contradictory propositions, which explains how both utterances can be correctdespite the fact that syntactically the sentence used in (1a) is the negation of the sentence used in (1b). By analogy, an utterance of "I am the queen of England." and an utterance of "I am not the queen of England." will not express contradictory propositions if uttered by different people, even though the second sentence is syntactically the negation of the first.

What kind of indexicality could be responsible for (1a) and (1b) not expressing contradictory propositions? On the face of it, the sentences uttered do not seem to contain any indexical elements. So, if we are to accept the conclusion that there is indexicality here, we will have to say that it is somehow beneath the surface. Now, the names "Depp" and "Pitt" do not seem to be context-sensitive in any way that could help here. So the assumption must be that the apparent 2-place predicate "is more handsome than" has a silent third argument place, one that is assigned a referent contextually. One way (but not the only way) in which all this might be true would be if the sentence used in (1a) were similar to the sentence "On my standard, Depp is prettier than Pitt.". For each utterer with a different standard, such a sentence would express a different proposition.

\footnotetext{
${ }^{18}$ Strictly speaking, there are at least two ways in which a sentence can semantically express different propositions in different contexts. It might be that the sentence is ambiguous, i.e. has several meanings, and different meanings are relevant to the different contexts. Or the sentence might have context-sensitive meaning which causes it to express different contents in the different contexts. For simplicity I mostly ignore the first possibility.
} 
An indexical proposal along these lines is the only way in which a standard semantic framework can save the possibility that neither Anna nor Barbara has violated any norms, or perhaps more precisely that neither of them has violated any norms that they are subject to. But such a proposal faces a number of problems which may motivate a relativist modification of the standard framework. Let us examine some of these problems.

A fairly superficial complaint would criticize the postulation of implicit syntactic structure. However, it would be hard to argue against implicit syntactic structures in general. But arguing that in this particular case postulating implicit structure is wrong would presumably amount to showing that there are acceptable alternatives. So this line of criticism would rest on a detailed examination of the alternatives-including relativism.

A more substantial set of criticisms revolves around the impression that any indexical proposal distorts the content of the utterances, for it claims that Anna and Barbara assert (and believe) propositions that concern their own standards, even though it seems that they are merely comparing Depp and Pitt without their assertions and thoughts having any reflective content. By itself, this is a fairly vague worry. But there are a number of concrete problems that crystallize the issue.

The first problem concerns attitude and speech reports. If the sentence "Depp is prettier than Pitt." were indexical in such a way that it expresses different propositions in (1a) and (1b), then we should expect speech-reports of such utterances to be sensitive to this difference. Speech reports are subject to the constraint that correct speech reports must adjust indexical elements in the utterance reported to any relevant changes between 
the context of the report and the context of the original utterance. For example, take our earlier example: if Oscar utters the words "I am hungry." at 12 noon, then a report by Alistair: "Oscar said that I am hungry." Would not correctly report Oscar's utterance, because "I" in the report would refer to Alistair. Similarly, if at 2pm Oscar reports his own 12 noon utterance with the words "I said that I am hungry.", then the report would be incorrect, or at the very least odd: the present tense of "am" in the report suggests that the reported utterance concerned the time of the report ("I said then that I would be hungry now" rather than "I said then that I was hungry then.)". The following general rule articulates some of these principles of speech reporting:

(SR) If a sentence $s$ is indexical in such a way that an utterance of $s$ in context $c 1$ expresses a different proposition from an utterance of $s$ in a context $c 2$, then an utterance by someone $A$ of $s$ in $c 1$ cannot be correctly reported in $c 2$ by using the form of words ' $\alpha$ said that s.' (where " $\alpha$ " is some term referring to A). ${ }^{19}$

Now consider the indexical hypothesis that (1a) and (1b) do not express contradictory propositions because "Depp is better than Pitt." contains an indexical which is sensitive to a change in context that occurs from (1a) to (1b) (for this is our proposed explanation of how both utterances are fault free). On this hypothesis, Barbara cannot, in the context of (1b) (or in a context relevantly like it) correctly report (1a) by saying "Anna said that Depp is prettier than Pitt.". For the sentence "Depp is prettier than Pitt." contains an indexical element which changes its content with the change from (1a) to (1b). However, this prediction is incorrect, for such a report by Barbara would clearly be correct. Thus the hypothesis is wrong.

\footnotetext{
${ }^{19}$ Single quotes are here used like corner quotes.
} 
It may be claimed that expressions like "local" or "enemy" are context-sensitive without meeting constraint (SR), and thus represent a relevant counterexample. Consider two utterances $(2 a)$ and $(2 b)$, one reporting the other:

(2a) John (in el Raval, Barcelona): "I met her in a local bar."

(2b) Ben (in Digbeth, Birmingham): "John said he had met her in a local bar."

The bar mentioned in (2a) is not in the surroundings of the place at which the report, $(2 b)$, is made, thus it seems that if $(2 b)$ is a correct report of $(2 a)$, then (SR) is false. ${ }^{20}$

However, such cases are not conclusive counterexamples to (SR). It seems to me that there are several construals of these examples on which (SR) is not affected. One construal would view report (2b) (in the envisaged context) as involving unmarked mixed quotation: the reporter is using the exact words of the reportee. Another construal, which I prefer, denies an underlying assumption about the way in which "local" is context sensitive. Let me explain. (2b) is a counterexample only if the context-sensitivity of "local" is such that it refers to different areas in the contexts of (2a) and (2b). For example, if we assume that "local" always picks out the surroundings of the place of utterance, then clearly "local" picks out disjoint areas in the two contexts. However, it is not clear that this is how the context-sensitivity of "local" works. A more plausible suggestion is that "local" picks out the surroundings of the place salient in the context of utterance. Thus, if prior to (2b), el Raval in Barcelona has been raised to salience, then that's the area "local" will pick out in it. If not, then not, but then (2b) would not seem a

\footnotetext{
${ }^{20}$ This type of counterexample is based on François Recanati's comments to my paper at the relativism workshop in Oslo in 2005. Thanks also to Darragh Byrne for discussion.
} 
felicitous report of (2a). Thus on this construal of "local", the case does not present a counterexample to $(\mathrm{SR})$.

Nevertheless, the objection to the indexical hypothesis that is based on (SR) is not conclusive. For there might be a class of context sensitive expressions that do not conform to (SR), i.e. expressions that do vary in content from context to context like ordinary indexicals, but whose content in attitude report contexts is determined not by the context of the report but by some other context (possibly the context of the attitude being reported). ${ }^{21}$ Claiming that sentences like the one used in (1a) are exceptions to (SR) would avoid the charge of being ad hoc only if there were further, independent cases. As we shall see below however, there is a surprisingly large range of cases that give rise to analogous problems. So a determined indexicalist could use this to defend herself against the charge of making ad hoc exceptions.

The second objection to the indexical hypothesis is this. The indexical hypothesis says that the propositions expressed by (1a) and (1b) respectively are not contradictorythey could both be true at once. As a consequence the indexical hypothesis predicts that Barbara could come to accept what Anna has asserted (and vice versa) without changing her mind. However, in reality it is clear that Barbara cannot come to accept what Anna has said without changing her mind. So the indexical hypothesis is wrong.

Obviously, more needs to be said to make this argument work. ${ }^{22}$ To begin with, one would need to consider various proposals on the exact nature of the indexicality of "Depp

\footnotetext{
${ }^{21}$ Thus, in terms used by Kaplan (1977), attitude report contexts are selective "monsters", i.e. they are monstrous with regard to some indexicals and not with regard to others. See Schlenker 2003 for extensive discussion.

${ }^{22}$ See my 2004 for some more detail on this argument with respect to the moral case.
} 
is prettier than Pitt". However, there are ways in which the indexical proposal can be saved. Let me sketch what I regard as the best move an indexicalist can make at this point. ${ }^{23}$ Suppose the precise hypothesis is that in any context of use, the sentence "Depp is more handsome than Pitt" expresses the proposition that the speaker of the context has a standard of taste that ranks the looks of Depp higher than those of Pitt. In other words, the sentence

(3) Depp is more handsome than Pitt.

is equivalent to the sentence

(3I) On my standard Depp is more handsome than Pitt.

in the sense that both sentences express the same proposition in any context of use. Now, how could one explain that Barbara cannot accept Anna's assertion? For if Anna were to utter (3I), then Barbara could perfectly happily say: "What Anna said is true. But still Depp is not more handsome.". This answer would be incoherent as an answer to an utterance of (3) instead, i.e. (1a). That this is so is not a matter of the contingent features of this situation, but rather seems to have to do with some permanent difference between (3) and (3I).

The thing to say here for the indexicalist is that (3) and (3I) do indeed differ in their meaning, even though they express the same proposition in any context. This is because the difference between them is not a difference in semantic content, but rather a difference in the presuppositions conventionally triggered by them. (3) triggers the presupposition that speaker and audience have standards that converge (at least in the case under discussion). (3I) does not trigger such a presupposition. That explains why

\footnotetext{
${ }^{23}$ See Lopez de Sa (this volume) and Kölbel 2007 for some more detail.
} 
Barbara cannot coherently accept Anna's assertion without changing her mind, even though — according to the indexicalist — she is perfectly happy to believe the proposition Anna asserted. The propositions that are according to the indexicalist asserted by Anna and Barbara in (1a) and (1b) are compatible, however, they are not compatible on the presupposition that Anna's and Barbara's standards converge, a presupposition that is conventionally carried by $(3){ }^{24}$

The problems with the indexical proposal show that it is not easy to account for cases like (1a) and (1b) within the standard semantic framework. It requires admitting exceptions to (SR) as well as making complex claims about non-truth-conditional aspects of the meaning of sentences like (3). I believe that this provides some motivation for looking into possible modifications of the standard semantic framework. In the next section I shall look at relativist proposals for modifying the standard framework in the taste case. After that I shall review other areas besides matters of taste, including epistemic modals, knowledge ascriptions and future contingents.

\section{Relativism about taste}

It was the assumption that utterances (1a) and (1b) are both correct that led to the conclusion that the sentences uttered must be context-sensitive in some way. One way to avoid the conclusion would be to oppose the starting assumption. One might point out that it is incoherent to accept both claims as true, and that therefore it is incoherent to deny that one of them is not true. And that would seem to show that it is incoherent to deny that one of them is at fault, given constraint (A1), i.e. the principle that asserting

\footnotetext{
${ }^{24}$ Can a similar account be given claiming that the presupposition is triggered not conventionally but conversationally? I doubt this, given that the impression of incompatibility between (1a) and (1b) is quite robust and not easily cancelled by providing further information about the situation.
} 
something untrue constitutes a fault. This is an important observation. However, the intuition that the two utterances may be correct and without fault survives it. It is coherent to maintain that both (1a) and (1b) are correct in the sense that neither violates any norm to which it's utterer is subject. While no-one can coherently accept what (1a) says and also accept what (1b) says, it remains coherent to say that it is correct for one person to accept the one, and correct for another to accept the other.

The relativist takes this idea quite seriously: there are propositions that it is correct for some people to accept (believe, assert etc) and not correct for others. Something closely analogous is already familiar from the standard framework: for actual people it is correct to believe the proposition that Carnap emigrated to the US. But it is not correct to believe this for non-actual people from a world in which Carnap never emigrated to the US. The proposition in question is contingent and thus varies in its truth-value from one possible world to another. The novelty of the relativist proposal is simply that it aims to allow that amongst actual people there may be differences as to what it is correct to believe.

Thus, instead of saying that the semantic content of the sentences in question varies with the context of use, the proposal is to say that while the content remains stable the content's truth-value varies not just with a possible world but also with an additional factor. The proposal is thus (at least initially) analogous to older and better known departures from the standard picture, such as temporalism. In Kaplanian terms, the proposal is that the circumstances of evaluation consist of a possible world and another parameter, in this case a standard of taste. So, the semantics still defines a three place sentential truth-predicate $\mathrm{T}(s, c, e)$, but now the third relatum of the truth-relation is a 
complex circumstance of evaluation $e=<w, p>$ consisting of a possible world $w$ and a standard of taste $p . .^{25}$

Just as one may legitimately ask "What is a possible world?", one can ask "What is a standard of taste?". My preferred answer to that question postpones the substantial issues until later: a standard of taste is a function from pairs of propositions and possible worlds to truth-values. ${ }^{26}$ This answer is very abstract. However, as I observed above in $\S 2$, semantic theories by themselves are a purely abstract affair in any case. The definition of a semantic truth-predicate for sentences is empirically irrelevant until we fill it with empirical content via an application principle on the model of (P) or (A1) and (A2). Similarly a revised semantics, which construes circumstances of evaluation as consisting of a possible world and a standard of taste, will be filled with empirical content only once we introduce some application principles.

To recall, the most simple application principle for standard semantics was $(\mathrm{P})$, the principle that an utterance is true just if the sentence uttered is true in the context of the utterance and the possible world of the utterance. Or in more picturesque terms: an utterance is true just if the proposition expressed by the sentence in the context of the utterance is true at the world of the utterance. The more refined and partial constraint (A2) said that an utterance is correct (fault free) only if the sentence uttered is true in the

\footnotetext{
${ }^{25}$ Some relativists, for example MacFarlane (e.g. this volume), increase the adicity of the truth-predicate to four, making truth a relation that relates a sentence with a context of use, a possible world and a "context of assessment". This is merely a notational variation. The discussion that follows can easily be transposed to MacFarlane's key.

${ }^{26}$ One might restrict the functions that qualify as standards of taste by saying that standards of taste are constant with respect to propositions that do not concern matters of taste. The substantial issues would remain to be answered.
} 
context of the utterance and the world of the utterance. Or in picturesque terms: an utterance is correct only if the proposition it expresses is true at the world of the utterance. What would be analogous principles for a relativist semantics?

In standard semantics, we select the world at which an utterance takes place as the value of the world parameter that is relevant for evaluating the utterance as correct. One possibility is to proceed analogously in the case of the standard of taste parameter. Thus, we might say that the context of an utterance determines one particular standard of taste which will be relevant for evaluating utterances as correct. We would then get analogues to (P), (A1) and (A2) along these lines:

$\left(\mathrm{P}^{\mathrm{R}}\right) \quad$ For all sentences $s$ and contexts $c$ : an occurrence of $s$ in $c$ is true just if $\mathrm{T}(s, c,<\mathrm{W}(c), \mathrm{S}(c)>)$.

(where $\mathrm{W}(c)$ is the world of $c$ and $\mathrm{S}(c)$ is the standard of taste determined by c).

$\left(\mathrm{A} 1^{\mathrm{R}}\right)$ An assertion of a proposition $p$ in a context $c$ is correct only if $p$ is true at $<\mathrm{W}(c), \mathrm{S}(c)>$.

$\left(\mathrm{A} 2^{\mathrm{R}}\right)$ For all sentences $s$ and contexts $c$ : an (assertoric, literal) utterance of $s$ in $c$ is correct only if $\mathrm{T}(s, c,<\mathrm{W}(c)$, $\mathrm{S}(c)>)$.

Now, a definition of utterance truth along the lines of $\left(\mathrm{P}^{\mathrm{R}}\right)$, and the corresponding normative principles about assertion, are completely analogous with standard semantics in that utterance truth comes out as absolute. A sentence and an utterance context together determine whether, if an utterance in that context were assertoric and literal, it would be true, and thus can meet the norms of assertion. The situation is exactly analogous to temporalism, where the time at which a sentence is uttered is the one relevant for the evaluation of an utterance. Following Recanati's (this volume) distinction 
between moderate and radical relativism, let me call this kind of approach to pragmatics "moderate". (MacFarlane (2005, forthcoming) calls a relativist semantics paired with a moderate pragmatics “non-indexical contextualism”. $)^{27}$

Before considering approaches that are not moderate, let me examine in more detail how a moderate approach could be implemented. The most important detail will be the way in which the function $\mathrm{S}$, as it occurs in $\left(\mathrm{P}^{\mathrm{R}}\right),\left(\mathrm{A} 1^{\mathrm{R}}\right)$ and $\left(\mathrm{A} 2^{\mathrm{R}}\right)$ is to be cashed out. We are familiar with the $\mathrm{W}$ function; i.e. with the idea that the context of an utterance determines a possible world, the world at which the utterance takes place. What is new is the idea that an utterance context determines a standard of taste. There are many possibilities:

(S1) $\quad \mathrm{S}(c)=$ the standard of taste of the speaker of $c$.

(S2) $\mathrm{S}(c)=$ the standard of taste of the audience of $c$.

(S3) $\quad \mathrm{S}(c)=$ the standard of taste most relevant to the purposes of the conversation at $c$.

There are many more possibilities. ${ }^{28}$ (S1) seems to be the most popular hypothesis amongst proponents of relativism. ${ }^{29}$ So I shall briefly explore one way in which $\left(\mathrm{P}^{\mathrm{R}}\right)$,

${ }^{27}\left(\mathrm{P}^{\mathrm{R}}\right),\left(\mathrm{A} 1^{\mathrm{R}}\right)$ and $\left(\mathrm{A} 2^{\mathrm{R}}\right)$ work by singling out, in each context of use, one privileged standard of taste. Alternatively, one could single out a range of standards (in each context) and say that correct assertion requires truth in relation to all or some of the standards in the range, in analogy with super- or subvaluationism (compare MacFarlane 2005a, p. 330). I would count these variations also in the "moderate" category, given that again a sentence and a context of use together determine a truth-value of sorts - though in this case we get truth-value gaps (at the pragmatic level). I myself have proposed this kind of approach for vague sentences (Kölbel forthcoming). 
$\left(A 1^{R}\right)$ and $\left(A 2^{R}\right)$ might be applied to Anna's and Barbara's utterances (1a) and (1b), if the S function is interpreted according to (S1).

First, it is necessary to explain the idea that speakers can "have" a standard of taste. My own idea here is that if I have a standard, then I should accept only propositions that are true in the actual world and on my standard. In the case of judgements about matters of taste, which standard I have will in part depend on my personal preferences and aesthetic responses to things. Thus, for example, only someone who prefers Depp to Pitt will have a standard of taste on which the proposition that Depp is more handsome than Pitt is true in the actual world. Standard possession is therefore a theoretical notion that models our idea that it depends on certain individual speaker features (e.g. their preferences) which propositions it is correct for them to believe, and ultimately to assert. $^{30}$

Now suppose that Anna and Barbara have a different standard of taste due to differences in their personal preferences and dispositions to respond aesthetically. Then we can explain why both utterances ((1a) and (1b)) may be correct, even though the propositions asserted by them contradict one another. The propositions asserted contradict one another in the sense that for each circumstance of evaluation $e$, if the proposition asserted by Anna is true at $e$, then the proposition asserted by Barbara is not

\footnotetext{
${ }^{28}$ Some possibilities will not be very interesting. For example any function $\mathrm{S}$ with a constant value would be useless with regard to the problem of understanding utterances (1a) and (1b).

${ }^{29}$ See for example Kölbel 2002, 2003, Lasersohn 2005, Recanati this volume, MacFarlane 2008.

${ }^{30}$ It is important to be aware that on this model of standard possession, people can make mistakes: they sometimes believe or assert propositions that are not true according to their own standard. For example, Barbara may come to believe, as a result of listening to Anna's utterance (1a), that Depp is more handsome than Pitt. She might later realize that this belief is a mistake, because she prefers Pitt.
} 
true at $e$, and vice versa. However, when evaluating the assertions (and beliefs for that matter) for truth, a different circumstance of evaluation is relevant to each assertion. The context of (1a) determines Anna's standard of taste, while the context of (1b) determines Barbara's standard of taste as relevant. So neither of them fails to be true in the sense of $\left(\mathrm{P}^{\mathrm{R}}\right)$; neither of them violates the norm expressed by $\left(\mathrm{A} 2^{\mathrm{R}}\right)$. That's why, in the absence of violations of any other norms, both utterances may be without fault.

The relativist with a moderate pragmatics can therefore claim to make sense of the idea that (1a) and (1b) are both correct (fault free) without giving up on the idea that the propositions expressed by the two utterances are contradictory.

It remains for me to discuss the possibility of an "immoderate" pragmatics, i.e. a pragmatics that does not use an absolute notion of utterance truth along the lines of $\left(\mathrm{P}^{\mathrm{R}}\right)$, $\left(A 1^{R}\right)$ and $\left(A 2^{R}\right)$ as a central assertoric norm. Departure from an absolute truth norm in pragmatics could have various motives. For example, we might be unable to find a suitable function $\mathrm{S}$ that determines the value of the new parameter for each context of use with respect to which assertions are to be evaluated. Or there may be a number of distinct and complementary pragmatic norms, each of which picks out a different value of the parameter as relevant. For example, utterers might be subject to the norm (a) to assert a proposition only if it is true on the audience's standard, but also subject to the norm (b) that they shouldn't assert a proposition unless it is true on any standard shared by all members of the audience and the speaker, and also subject to the norm (c) that they shouldn't assert a proposition unless it is true on either Paul Bocuse's standard or Ferran Adriá's standard. Perhaps these norms are weighted: some are more important, and can overrule others. Under those circumstances it might be appropriate to say that there is no 
single value of the standard of taste parameter that is pragmatically relevant. In that case no interpretation of $\mathrm{S}$ will yield a correct principle $\left(\mathrm{P}^{\mathrm{R}}\right)$, or $\left(\mathrm{A} 2^{\mathrm{R}}\right) .^{31}$

There is no reason, prima facie, to suspect that this sort of pragmatics cannot work. ${ }^{32}$ However, any such pragmatics will have to offer an alternative to the model of communication that moderate approaches offer. Those advocating moderate approaches can say that audiences know under what conditions an assertion is correct, and thus can, if they have reason to assume that an assertion is correct, come to believe that those conditions obtain. Any immoderate pragmatics will have to find a replacement for this story. MacFarlane (2003, 2005, this volume) has on several occasions begun to tell such a story. It would depend on the details of such a story how the apparent faultlessness of utterances like (1a) and (1b) can be explained. I will briefly return to immoderate approaches in the next section when discussing the case of future contingents.

This concludes my exposition of the alternative, relativist account of Anna's and Barbara's utterances, and correspondingly the relativist account of the semantics of sentences concerning matters of taste. In the next section, I shall review a number of further cases in which similar issues arise, or in which similar relativist solutions seem at least initially promising.

\footnotetext{
${ }^{31}$ Very abstractly speaking, all theories that distinguish between semantic content and content otherwise conveyed (Grice being the classic example), can be seen as immoderate pragmatics. On Grice's view, clearly various norms compete, namely the various conversational maxims, and a delicate process weighs these norms against one another.

${ }^{32}$ Evans 1985 seems to think that only a moderate pragmatics is feasible. Recanati's and GarcíaCarpintero's contribution to this volume discuss Evans' arguments and come to a similar conclusion.
} 


\section{Hidden indexicals or Relativism in other cases}

The problem of accounting for the possibility of superficially contradictory utterances that are nevertheless fault free, and the range of possible responses-indexical or relativist - is not unique to discourse about matters of taste, even though perhaps this is the case that is most intuitive. The same problem and responses recur with remarkable similarity in a wide range of further cases, some of which I shall now briefly review. I shall only expound the initial motivation and remark on some specific differences. It will be left to the reader to restore the detail provided in the taste case to the other cases.

\section{Epistemic Modals:}

Imagine Anna is trying to find out who emptied her bottle of whisky. At the beginning of her investigations, at time $\mathrm{t} 1$, she thinks that it might have been Barbara, because at that time she has no evidence that rules out the possibility of Barbara having emptied the bottle. Much later, at $\mathrm{t} 2$, she finds out that Barbara could not have emptied the bottle because she was not in town at the relevant time. Anna makes two utterances:

(4a) Anna at t1: "It might have been Barbara."

(4b) Anna at t2: "It might not have been Barbara."

Let us assume that the contexts of (4a) and (4b) are such that in both cases "it" picks out the same emptying of the same whisky bottle. Thus, on the face of it the two utterances look like the assertion and denial, respectively, of the same epistemic possibility. The utterances seem to express contradictory propositions: the proposition that it might be the case that Barbara emptied the whisky bottle and the proposition that it might not be the case that Barbara emptied the whisky bottle. Nevertheless, there is a clear sense in which Anna is right both times. Given that her knowledge at $\mathrm{t} 1$ does not rule out the possibility 
in question ${ }^{33},(4 a)$ is the right thing to say (and think) at t1. Given that her state of knowledge at $\mathrm{t} 2$ does rule out the possibility in question, (4b) is the right thing to say (and think) at $\mathrm{t} 2$. Both utterances comply perfectly with the norms of assertion.

As in the taste case, there are two main ways in which one can accommodate the impression that both utterances are correct (without giving up on the idea that truth is a norm of assertion). First, one could make a diagnosis of hidden indexicality: the propositions expressed by (4a) and (4b) respectively are not contradictories, for the sentences used exhibit a form of indexicality that causes some change of reference from t1 to 2 . For example, the first sentence used might be equivalent to

(4a*) Anna at t1: "My current state of knowledge is compatible with it having been Barbara."

As in the taste case, the indexical hypothesis generates various seemingly problematic predictions. One prediction concerns speech reports. We would expect, given (SR), that Anna cannot, at t2, correctly report her utterance (4a) homophonically. (4a*) clearly could not be reported homophonically at $\mathrm{t} 2$. However, contrary to this prediction (generated from (SR) and the indexical hypothesis), a homophonic report at $\mathrm{t} 2$ is perfectly correct: "I said that it might have been Barbara.". Explaining this would require dropping (SR) and saying that the hidden indexicals differ from ordinary indexicals. A similar complaint is that Anna might add at t2: "But I was wrong. For it could not have been Barbara.". ${ }^{34}$ If the indexical hypothesis were correct, one would not expect this. One would expect her to continue to endorse the proposition asserted at t1: "What I said was

\footnotetext{
${ }^{33}$ And perhaps given there is also no easy way in which Anna could have obtained such knowledge. See DeRose 1991.

${ }^{34}$ See MacFarlane forthcoming a, for a version of this argument against an indexical view.
} 
true: my knowledge at $\mathrm{t} 1$ did not rule out Barbara being the perpetrator.". But it might be argued that this is not how we would retrospectively assess such an utterance. ${ }^{35}$

The problem is that the way we report utterances like (4a) and (4b) and the way we evaluate them sometimes suggests that they have contradictory contents, and an indexical hypothesis cannot easily accommodate that. It seems that after the new information has come in Anna re-assesses the same content from a different perspective, namely that of the knowledge that she now has. Thus again a relativist construal is a natural alternative: the proposition in question varies in truth value with an extra parameter in the circumstances of evaluation. The proposition that it might have been Barbara is true relative to Anna's earlier state of knowledge, and it is false relative to her later state of knowledge. $^{36}$

A moderate pragmatic account could easily deliver the result we need, namely that both (4a) and (4b) are in compliance with the norms of assertion. The most plausible account, it seems, would say that an assertion of the proposition that it might be that $p$ is only correct if the speaker's knowledge is compatible with $p .^{37}$

\footnotetext{
${ }^{35}$ But compare the objections Wright raises against this reasoning in the article that appears in this volume.

36 Relativism about epistemic modals is defended by Egan, Hawthorne and Weatherson 2005 and MacFarlane forthcoming a. See also Egan 2008 and Gillies \& von Fintel 2006.

${ }^{37}$ Some uses, howeer, would suggest that it is not always the speaker's knowledge that is relevant. For example, consider the game show host who says: "The prize might be behind this door." while knowing it is not. Compare Gillies \& von Fintel 2006, Bach 2006 and Egan 2008.
} 


\section{Knowledge attributions:}

One of the areas of most active debate in recent epistemology has been a position called "contextualism about knowledge". ${ }^{38}$ According to the most common form of this view, sentences used for knowledge attributions, such as "Charles knows he has hands.", are context-sensitive in unobvious ways. The sentence is obviously indexical because in different contexts of use, it will concern different times in Charles' life. The contextualist's claim is that the sentence "Charles knows he has hands." is in addition sensitive to the standard of knowledge associated with the context of use. Thus, in a context $\mathrm{C} 1$ (perhaps when waking up in hospital after a horrific accident), the standards required for knowledge are relatively low: Charles' feeling his right hand with his left and vice versa may be enough for knowledge that he has hands. But in the context $\mathrm{C} 2$ of discussing scepticism, when a sceptic has just raised a sceptical possibility—perhaps that of Charles being a handless brain in a vat tricked by a computer into thinking he has got feelings in his hands - the standard sufficient for knowledge is much higher. Thus the following two of Anna's utterances may both be correct:

(5a) Anna at C1: Charles knows (at noon 1/1/2007) that he has hands.

(5b) Anna at C2: Charles does not know (at noon 1/1/2007) that he has hands. ${ }^{39}$

Being able to say that knowledge attributions vary in this way with the contextual standards for knowledge enables contextualists to give an answer of sorts to sceptical

\footnotetext{
${ }^{38}$ Cohen 1986, DeRose 1992, Lewis 1996 are classic articulations. For a recent overview of the vast literature on this topic see Rysiew 2007.

${ }^{39}$ I added the time specification in order to highlight that the contextualists are not talking about ordinary time-sensitivity of knowledge attributions. In other words, they are not claiming that Charles "forgets" that he has hands from $\mathrm{C} 1$ to $\mathrm{C} 2$ (or that he "learns" that he has hands, in case $\mathrm{C} 2$ precedes $\mathrm{C} 1$ ).
} 
arguments. It allows them to concede sceptical conclusions such as that expressed by (5b) when faced with a sceptical argument, without having to give up all or even most claims to knowledge. For (5a) and (5b) are both correct.

This result is achieved, in ordinary forms of contextualism, through the type of indexical hypothesis with which we are by now familiar. The sentence

(6) Charles knows (at noon 1/1/2007) that he has hands.

is claimed to be more or less equivalent to the sentence

(6I) By the currently salient standards for knowledge, Charles knows (at noon $1 / 1 / 2007)$ that he has hands.

Thus, the two utterances (5a) and (5b) do not express contradictory propositions. Rather, (5a) expresses the proposition that Charles meets C1's standard for knowing (at noon $1 / 1 / 2007)$ that he has hands, while (5b) expresses the proposition that Charles fails to meet C2's standards for knowing the very same thing. Postulating a hidden form of indexicality enables the contextualist to claim that both (5a) and (5b) are true.

The parallelism with the previous cases is not difficult to detect. Similarly, it is not difficult to see that the indexical hypothesis will be subject to some of the same problems that arose for the indexical solutions in the previous cases. Thus, for example, it would seem to be correct to report (5a) in C2 by saying "Anna said that Charles knows that he has hands.". Indeed, if one pointed out to Anna after her utterance (5b) that she said earlier that Charles does know that he has hands, then it would be quite normal for her to say: "Yes, I did say that. But I was wrong.". These observations seem to be in conflict with epistemic contextualism in the form currently discussed. ${ }^{40}$

\footnotetext{
${ }^{40}$ See Yourgrau 1983 and Kompa 2002 for similar observations about contextualism.
} 
Again, a form of relativism has been offered as an alternative. ${ }^{41}$ Instead of saying that sentences like (6) express different propositions in different contexts of use, due to variations in the relevant standards for knowledge, we could say that the proposition expressed remains constant but that the constant proposition expressed is unusual in that it varies in its truth-value with an extra circumstantial parameter. Rather than complicating the function from context of use to content (i.e. the character) by adding parameters to the context, we instead complicate the function from circumstances of evaluation to extensions by adding a circumstantial parameter. ${ }^{42}$

Again, relativists about knowledge attributions will have to say something about how the changes in the semantics affect the pragmatics, and settle on a moderate or immoderate approach. I believe that the mainstream of contextualism is a form of attributor contextualism, thus the most obvious starting point would be a moderate pragmatics in which the context of use determines a relevant standard for knowledge against which that utterance is evaluated. However, MacFarlane (2005b) argues that an adequate pragmatics must allow us to evaluate the same utterance by recourse to varying standards.

\section{Moral Values:}

The case of moral value is largely similar to that of aesthetic value already discussed at length. However, in the moral case, the driving assumption that there is some extra factor

\footnotetext{
${ }^{41}$ See MacFarlane 2005b.

42 As pointed out earlier, MacFarlane (2005b) prefers to introduce in addition to context of use and circumstance of evaluation, a "context of assessment". However, as he as confirmed in correspondence, the choice between adding the new parameter to the circumstances of evaluation or introducing a new context of assessment, is a matter of presentation, not of substance.
} 
on which value depends is much more controversial. To give a very brief sketch, let as consider two utterances, one made in an Indian moral context by Arvind, one made in a Western European moral context by Barbara

(7a) Arvind in C1: One ought not to marry outside one's own caste.

(7b) Barbara in C2: It's not the case that one ought not to marry outside one's own caste.

Now, to say that both of these utterances may be correct is highly controversial, by far more controversial than in the taste case. Nevertheless, some philosophers and some anthropologists have been driven by a variety of different considerations to the conclusion that moral judgements depend for their correctness on some implicit parameter such as a moral code. Usually positions of this sort are called "moral relativism". However, the best known position that goes under that name, namely Harman's moral relativism ${ }^{43}$, is actually a thesis of hidden indexicality. Again, (7a) and (7b) do not express contradictory propositions and this explains the (controversial) starting datum that neither (7a) nor (7b) were mistaken. Much the same problems have been pointed out with this indexicalist view, and a relativist version (in the current sense of "relativist") has been suggested. ${ }^{44}$ So far, the associated pragmatic approach that has been proposed is moderate.

\section{Painted Leaves:}

There is a seemingly unrelated debate in theoretical linguistics and the philosophy of language about the general role of context in linguistic communication. Contextualists, in

\footnotetext{
${ }^{43}$ Harman 1975. See also Dreier 1990 and 1999.

${ }^{44}$ See Kölbel 2002, 2004 and 2007.
} 
this debate, challenge a certain traditional model of linguistic communication associated with formal semantics. The formal semanticists believe that the linguistic meaning of a natural language sentence will determine for each context of use a proposition that it semantically expresses at that context. The route from context to proposition expressed is, according to the traditionalists, a purely mechanical one completely anticipated by the semantics of the sentence used. The paradigm for this role of context is given by typical indexical expressions such as "I" or "here" or "now". However, according to contextualists, the route from context to content is not one that can be anticipated in this way in a semantic theory. Contextualists put much more emphasis on pragmatic processes of determining which proposition is expressed by any particular utterance. They often claim that a sentence by itself together with the context of use only determines an incomplete or truncated proposition, one that needs completion via an interpretive process of "free enrichment". Now, the cases presented by contextualists in support of their view bear an uncanny resemblance to the sort of cases we have been discussing.

One of the best known examples is from Charles Travis (1997). Suppose Pia utters the sentence "The leaves are green." twice, once talking to a photographer who is looking for a green motif, and once talking to a botanist looking to classify the plant in question. The twist is that the leaves that each of the utterances refers to are the leaves of a Japanese maple. As is normal with Japanese maples, the leaves were originally russet in colour. But subsequently they have been painted green. According to Travis (1997), the first utterance is true, while the second utterance is false. The lesson is supposed to be that a semantic rule alone cannot anticipate which propositions might be expressed by a 
sentence in which contexts, and more examples on the same model can be easily constructed.

The typical defensive move of a traditional semanticist would be to insist that even though the utterances may convey or communicate different propositions which then differ in truth-value, the proposition semantically expressed by the two utterances are the same. Thus, the formal semanticist might say that both utterances are true, but the second is misleading in that it also pragmatically conveys a false proposition, namely that the natural colour of the leaves is green. Or she might say that they are both false, but that the first one also pragmatically communicates a true proposition, namely that the leaves are superficially green. The problem Travis points out is that the formal semanticist cannot offer a reason to prefer one of these two options to the other. Now, if this problem were restricted to only one case, it might have been feasible to provide some rationale for preferring one of the options. However, given that many more examples can be constructed, this will not remove the problem.

Now, in order to preserve the continuity with the earlier discussions, let me adjust Travis' example. Consider two utterances of superficially contradictory sentences:

(8a) Pia in $\mathrm{C} 1$ : The leaves are green. [directed to a photographer who is looking for something green as background for his photo]

(8b) Pia in C2: The leaves are not green. [directed to a botanist who is trying to classify the tree]

There is a strong intuition that both utterances are correct. How can we accommodate that intuition in a traditional semantic framework? As before, we have an indexical and a relativist option. According to the indexical option, the predicate "is green" is indexical 
in such a way that in $\mathrm{C} 1$, it expresses a property that applies to the painted leaves, and in C2 it expresses a property that does not apply to the leaves. Thus the propositions expressed in (8a) and (8b) do not contradict one another. By contrast to the previous cases, it is not easy to generate intuitions about speech reports or retrospective evaluations that would create a problem for an indexical proposal. However, there are other reasons why it seems ill-advised to postulate hidden indexicality in this case. If the current case provides evidence for "is green" being indexical in the way suggested, then it is likely that we will be able to find evidence for the indexicality of any predicate whatsoever. For Travis-style examples abound. ${ }^{45}$

The conclusion contextualists want to draw is that a formal semantic theory for a language just cannot spell out in advance the semantic contents that will be expressed by the language's sentences in all possible contexts. A form of relativism may help avoid this conclusion: instead of concluding that the propositions expressed by sentences vary in unpredictable ways from context to context, we can say that the propositions predictably expressed by sentences in contexts are evaluated, and used in communication, in unpredictable ways. The proposition expressed by the sentence "The leaves are green." remains invariant as long as we are talking about the same leaves at the same time. However, whether that proposition counts as true, whether asserting it counts as correct, depends on the specific purpose against which we are evaluating that proposition. We cannot in advance predict for what purposes people may venture to assert the proposition that those leaves are green at that time. ${ }^{46}$ Thus again, we need to add a new parameter to

\footnotetext{
${ }^{45}$ This is the slippery slope of which Cappelen \& Lepore warn us in their 2004.

${ }^{46}$ Stefano Predelli's (2005) answer to Travis' problem seems to follow roughly these lines. MacFarlane has also offered a similar answer to context-shifting arguments in his forthcoming b. In MacFarlane's
} 
the circumstances of evaluation: propositions have their truth-value relative to pairs $<w$, $p>$ of a possible world $w$ and a purpose $p$.

As before, once the circumstances of evaluation are enriched, the relativist also needs to say something about the normative significance of truth in pragmatics. The impression that (8a) and (8b) are fault free will need to be explained by reference to some pragmatic account. If the purpose (or purposes) relative to which we evaluate an utterance are completely determined by the sentence used and the context of use, then a moderate pragmatics will do. However, if there is a possibility that the very same utterance may be evaluated now against this, and now against that purpose, then a more sophisticated pragmatics will need to be construed.

\section{Future Contingents:}

The case of claims about the contingent future differs considerably from the previous ones. ${ }^{47}$ While this is again a case where certain considerations support the view that certain propositions vary in truth-value with a non-standard parameter, the variation is never from false to true, or from true to false. Rather, the variation occurs either between having no truth-value and being true, or between having no truth-value and being false. For this reason, I shall in this case consider two utterances of the same sentence, one made in 2005, and one made in 2007:

(9a) Italy are the winners of the 2006 Football World Cup. [uttered in 2005]

terminology, an invariant proposition can have a varying intension, rather than the proposition being the intension and varying in truth-value not just with a possible world, but also with a purpose.

47 The main arguments presented in this subsection are drawn from MacFarlane 2003 and from MacFarlane's contribution to this volume. 
(9b) Italy are the winners of the 2006 Football World Cup. [uttered in 2007] ${ }^{48}$ The sentence used appears to be eternal (i.e. it seems to express the same proposition no matter when it is used). Since (9b) is in fact true, this would mean that (9a) must also be true. However, indeterminism requires that utterance (9a), at least when made, was not true, for it was not yet determined in 2005 that Italy would win in 2006. Mere semantics should not settle controversial metaphysical issues, so the indeterminacy in truth-value of (9a) should at least be an option within our semantic framework. So the truth of the sentence used in (9a) and (9b) should be made, somehow, to depend on a new parameter of time: the sentence is not true (and not false) in relation to times earlier than the 2006 World Cup final, but true relative to all other times.

Might we allow a variation in truth-value between (9a) and (9b) by postulating extra indexicality and saying that after all the two utterances express different propositions? No simple indexical solution will work, for the problem can be raised just as easily with just one utterance. Consider utterance (9a). It seems that before the 2006 World Cup final, (9a) is not true, because the future is open. But after the 2006 World Cup final, when considering whether utterance (9a) was true, we'll have to say that it was true. Thus the very same utterance is true when assessed after the crucial time and not true when assessed before. But if the variation in truth-value concerns the very same utterance, then the variation cannot be due to a variation in the context of use, for we are talking about the same utterance. What has changed is simply the perspective from which we assess the utterance.

\footnotetext{
${ }^{48}$ In order to maintain the parallelism with the previous cases, I have deliberately chosen a sentence where the tense does not mark the relationship between the events described and the time of utterance.
} 
Is this another case where we need to introduce a new truth-determining factor in the semantics? A little reflection shows that not. The way to think about the open future is to take any event, e.g. an utterance, to be "located in" or "compatible with" a range of possible worlds, namely the range of worlds that coincide with the past up to that point. Given that the past does not completely determine the future, there will be more than one possible world that shares an event's past, each one corresponding to one way the future might turn out. On this view, the semantics can remain completely standard: a definition of sentential truth $\mathrm{T}(s, c, w)$, where $s$ is a sentence, $c$ is a context of use and $w$ is a possible world. The interesting questions begin when we ask whether a particular utterance is true. If we maintain that the future is open, then a context of use will not determine one particular world of a context, but at best a range of worlds. Thus we cannot follow the model of the simple application principle (P) above, which said that an utterance is true just if the sentence used is true at the context in which the utterance was made and at the world of that context. For there is no "world of the context", but rather a range of worlds that is compatible with the context.

Mac Farlane proposes to define a notion of utterance truth that varies even if the sentence uttered and the context of use are held fixed. (In other words, such a notion of utterance truth must be immoderate, because a sentence together with a context of use do not yet determine a truth-value.) Utterance truth will vary, then, with the a "context of assessment", i.e. a concrete situation at which a proposition can be assessed. A context of assessment, just like a context of use, determines a range of worlds that are compatible with the past preceding that context. We can then define the truth of an utterance at a context of assessment in such a way that if a context of assessment is compatible only 
with worlds in which the utterance is true, then the utterance is true at that context of assessment. ${ }^{49}$ Thus, (9a) as assessed now is true, but it was not true as assessed before the 2006 World Cup final (because any context of assessment prior to that time is compatible with some worlds where (9a) is false). Any proponent of such a framework will have to offer some further considerations as to how an immoderate pragmatics explains communication, for example by showing how an utterance made in one context can be subject to the norm that that utterance be true in relation to certain future contexts of assessment.

There are some alternatives to this relativist framework. One alternative to relativism is a sophisticated kind of indexicalist proposal. We could say that utterances like (9a) are indexically about one particular possible future, however, which future that is is still indeterminate at the time the utterance is made. So, no determinate proposition is expressed by (9a), and this explains why in 2005, (9a) is neither true nor false. But why is (9a) true as assessed in 2007? Because all the propositions (9a) might express in 2007 are in fact true. This is an elegant solution. However, the problem with it is that Anna's utterance, like other utterances about the future, already seems to have a content in 2005 . Anna manages to express a proposition already at the time of utterance, and, if the utterance was sincere, Anna believes this proposition in 2005, and those in Anna's audience who believe what she told them also believe this proposition already in 2005 . It

\footnotetext{
${ }^{49}$ In the case in which the worlds compatible with the context of use is a proper subset of the set of worlds compatible with the context of assessment. This complication is explained in detail in MacFarlane's contribution.
} 
would be complicated to maintain all these claims if we wanted to say that Anna's utterance only begins to express a proposition much later. ${ }^{50}$

Another alternative is supervaluationism: the view that an utterance is true if the proposition expressed by it is true in all worlds that are compatible with the context of use in which the utterance was made, that it is false if it is not true in any of these worlds, and that it receives neither truth value if is true in some but not in others. This means that utterance truth is gappy: some utterances, like (9a), are neither true nor false. This does justice to our assessment of (9a) in 2005. But does it makes room for our evaluation of (9a) as true when we assess it in 2007? MacFarlane's contribution to this volume will provide an answer.

\section{Further cases: probability, fiction, vagueness}

There are at least three further potential areas of application for the relativist strategy. First, on a subjectivist construal of probability, probability ascriptions are plausible candidates for a relativist treatment similar to that of epistemic modals. ${ }^{51}$ Whether it is right for some thinker to call some outcome probable will depend on the evidence available to that thinker or even on the probability function with which that thinker started out.

Another case of application is that of fictional utterances. The very same sentence, for example "Mozart's requiem was commissioned by Salieri." can be used to make a correct remark about Forman's movie Amadeus, and an incorrect remark about the real

\footnotetext{
${ }^{50}$ We would have to introduce new entities that can figure as the objects of Anna's assertion and belief, entities that can vary in their truth-value with the time of assessment, i.e. entities that are quite similar to the propositions of the relativist.

${ }^{51}$ See Price 1983 and Kölbel 2002 for some discussion.
} 
world. The standard treatment involves the postulation of contextually implicit operators. ${ }^{52}$ However, implicit operators can be avoided if one takes seriously the idea that the truth of a proposition can vary with an extra parameter. ${ }^{53}$ The extra parameter is presumably something like a possible world, so that the world of Forman's Amadeus and the actual world can figure as values of such a parameter. ${ }^{54}$ If such a parameter is allowed, we can be much more differentiated in the pragmatic evaluation of utterances as true, and thus do justice to the impression that the very same proposition-that Salieri commissioned Mozart's requiem — can be asserted correctly in one context and incorrectly in another.

Finally, a "sharpening" parameter has been proposed in the semantics of vague predicates and gradable adjectives. Supervaluationists have long used this to deal with the sorites paradox. ${ }^{55}$ A supervaluationist semantics starts by defining an auxiliary relativized truth-predicate $\mathrm{T}^{\mathrm{A}}(s, c,<w, p>)$ which relates a sentence $s$ to a context $c$ and a pair of a possible world $w$ and a sharpening $p$. They then proceed to define truth proper as truth in all sharpenings: For all $s, c, w$ : $\mathrm{T}(s, c, w)$ iff for all $p: \mathrm{T}^{\mathrm{A}}(s, c,<w, p>)$. The result is a three-valued semantics with some associated problems. Now some of these problems can be avoided if we accept the auxiliary truth-predicate $\mathrm{T}^{\mathrm{A}}$ as the ordinary semantic truthpredicate. It will then be a task for the pragmatics to deal with the extra sharpening

\footnotetext{
${ }^{52}$ For example, Field 1973 and Lewis 1978.

${ }^{53}$ The basic idea for this is contained in Predelli 1997, 2005. However, Predelli seems to have changed his mind - see his 2006 .

${ }^{54}$ However, the job of the new parameter cannot be done by the standard possible world parameter. For there are possible worlds in which Salieri does commission the requiem and Forman's fiction portrays him as not commissioning it.

${ }^{55}$ The classic source is Fine 1975.
} 
parameter, for example by specifying that it is correct to assert a proposition only if it is true in all sharpenings, thus in effect giving a "supervaluational pragmatics". 56

\section{Outlook and interaction of the various parameters}

Given that I have just described 9 different candidate areas for relativist treatment, the question naturally arises how the different parameters of relativization would interact. Suppose we were articulating a semantics for a language that contains, for example, both epistemic modals and predicates of personal taste. Should our semantics construe the circumstances of evaluation as incorporating two separate new factors, namely a state of knowledge and a standard of taste? The semantic truth-predicate would relate a sentence with a context of use, a possible world, a state of knowledge and a standard of taste. Or can we rationalize and add just one multi-purpose parameter?

I cannot treat this question properly here. However, it is clear that the answer will in part depend on whether there are operators (in analogy with modal operators) that shift the new parameters, and how they interact with one another. Thus, for example, suppose we have an complex operator "For $N$, $p$ " which shifts the taste parameter to the standard of taste of $N$, so that "For Anna, Depp is more handsome than Pitt" is true relative to a context, world and standard of taste just if "Depp is more handsome than Pitt." is true relative to that context, that world and Anna's standard of taste. ${ }^{57}$ Now, given that such

\footnotetext{
${ }^{56}$ This sort of approach was proposed by MacFarlane at the ESAP conference 2002 in Lund. One version of the approach is defended in more detail in Kölbel forthcoming a. See also Richard 2004.

${ }^{57}$ See Kölbel 2008. If natural langages contain constructions that are best treated as operators that shift a novel circumstantial parameter, then this would of course constitute a powerful argument in favour of introducing such a parameter. However, a case will have to be made that such an operator treatment is better than a correspondinf quantifyer treatment, which would naturally go with the corresponding indexicalist position.
} 
an operator shifts the taste parameter without shifting the world parameter, we can't rationalize and fuse the world and taste parameters together. ${ }^{58}$ If there is a similar operator shifting the state of knowledge parameter separately, then that would presumably constitute a reason to maintain a separate state of knowledge parameter. More interesting questions arise concerning the mutual embedding of such operators and resulting scope issues. ${ }^{59}$

Whatever the outcome of future research in this area, I believe that the number and breadth of areas in which a relativist approach can be motivated shows that there are general underlying issues here that require principled research. There may be a lot wrong with recent proposals of relativism, but it is not that they are ad hoc or lack motivation.

\section{Overview of the contributions to this volume}

For better orientation, the contributions to this volume have been ordered according to their focus. There are four parts. Part I contains essays that elaborate relativism in one way or another. Part II contains two papers considering the metaphysical consequences of relativism. Part III consists of papers that offer detailed objections to relativism. And finally Part IV comprises three papers that offer alternatives to relativism.

François Recanati opens the first part with an essay that explains the parallelism between recent forms of relativism (for example about epistemic modals and gradable adjectives) and temporalism, the view that there are tensed propositions, propositions whose truth-value varies with time. He defends these forms of relativism against two classic objections that have been levelled against temporalism, namely those by Gareth

\footnotetext{
${ }^{58}$ See Einheuser's contribution to this volume.

${ }^{59}$ Bonnay and Egré, in this volume, undertake a detailed examination of the interaction of a possible world parameter and a perspectival parameter.
} 
Evans and Mark Richard. However, his defense extends to moderate forms of relativism only.

Stefano Predelli and Isidora Stojanovic elaborate relativistic semantics in a different respect. They offer a detailed account of the effects on Kaplan's (1977) semantics if it is modified in a relativist way, and in particular if what they call Kaplan's "Classical Reduction" (none other than principle (P) in $\S 3$ above) is abandoned. They examine in detail how the interaction between indexicality and intensionality is affected by relativism.

John MacFarlane has been one of the pioneers of the recent wave of interest in relativism, as well as arguably its strongest proponent, having defended a relativistic view in a wider range of cases and in more detail than anyone else. His prize-winning 2003 paper "Future Contingents and Relative Truth" was the starting point of much further research, by others and by MacFarlane himself. Here he returns to the case of future contingents, revising the case he originally made. He shows how his own original argument against the main competitor to relativism in this area, supervaluationism, can be resisted. However, he also presents a new argument to the effect that supervaluationism, unlike relativism, cannot account for our use of the "actually" operator.

Denis Bonnay and Paul Egré propose a novel and specialized application of relativism. A margin for error principle for knowledge says that one knows that $p$ only if in a situation that is indistinguishably different from one's own, $p$ is still the case. Epistemicists about vagueness use this principle to explain why we cannot have knowledge of borderline cases. A KK-principle says, roughly, that when one knows that $p$ one also knows that one knows that $p$. These principles are well-known to be 
incompatible because, roughly, each time we iterate knowledge more, the margin for error required for knowing becomes wider. So if knowledge implies knowledge that one knows, then the margin for error must be maximally wide. Thus no contingent knowledge would be possible, if both the margin for error principle and the KK-principle were true. Williamson consequently rejects the KK-principle. However Bonnay and Egré propose an ingenious way of making versions of the two principles compatible. Their proposal involves adding a new, perspectival parameter in the circumstances of evaluation, a parameter that captures what a subject of knowledge knows, thus making use of the relativist strategy. ${ }^{60}$

Manuel García-Carpintero develops a differentiated view about relativism. After assessing what is at stake in discussions about relativism, he argues that radical versions of relativism are untenable. In particular, he argues against such a view in the case of gradable adjectives. On the other hand, he defends a version of moderate relativism for the same case.

Part II contains two essays exploring the metaphysical consequences of relativism. In the first, Crispin Wright distinguishes two versions of relativism. One version says that propositional truth is a ternary relation that relates a proposition with a world and a perspective of sorts. On this view, propositions can no longer be viewed as properly representational of the world. The other version says that propositional truth continues to

\footnotetext{
${ }^{60}$ Bonnay and Egré model their idea by modifying the standard Hintikka epistemic semantics which involves an impersonal "It is known" epistemic operator, thus it is not straightforward to compare their project with that proposed by, for example MacFarlane in his 2005b. However, I think it is safe to say that Bonnay and Egré's perspectival parameter has a different function from MacFarlane's and thus should count as a separate application of the relativist strategy.
} 
be a binary relation relating propositions with worlds, however, on this view some worlds are accessible only from certain perspectives. He goes on to draw out a number of important consequences of the version that claims propositions to be nonrepresentational.

Iris Einheuser also explores the metaphysical consequences of relativism in the cases of matters of taste as well as epistemic modals. Sticking for the moment to matters of taste, relativists will claim that propositions about matters of taste should be evaluated relative to a possible world and a standard of taste. Einheuser proposes a form of relativism — "fact-relativism" — that is akin to Wright's second version, i.e. one according to which propositional truth is binary, relating a proposition with a possible world. She shows that this requires a novel conception of possible world, according to which each possible world consists of an objective "substratum" and a standard of taste. This adjustment has the radical-sounding consequence that people with different standards of taste inhabit different worlds. Einheuser prefers such an accont because it maintains the close link between what a propositional content represents and the facts. If we want to say that propositions have their truth-values perspectivally, we should therefore conclude that the facts represented by these propositions are likewise perspectival.

Part III contains three essays that mount detailed objections to relativism. Sebastiano Moruzzi tries out versions of the classic self-refutation objection against MacFarlane's relativism as applied to matters of taste. He concludes that a fourth version of the objection provides a significant challenge because it shows that relativists cannot explain how a dispute on a matter of taste can be rational. 
In his paper, Sven Rosenkranz, objects to relativism about matters of taste primarily on the grounds that it does not respect what he regards as an unassailable Fregean truth, namely that to assert a proposition is to present it as true simpliciter, and similarly that one can derive the correctness of an assertion that $p$ from $p$. He also points out that if assertion is not regarded as involving these norms of correctness, for example if to assert is merely to present as true on one's own standard, then a case where one person asserts that $p$ and another asserts that not- $p$ is not a proper disagreement.

Richard Dietz offers a detailed criticism of relativism concerning epistemic modals. Relativists claim that when assessing a claim of epistemic possibility (e.g. "There might be a counterexample.") one will assess it against the state of knowledge of the assessor at the time of the assessment. Thus, when I first claim that there might be a counterexample to Goldbach's conjecture, and later find a proof of it, then at the later point I will say that my earlier claim was wrong. Dietz points out that this may be the case in the example just given, but that in cases where the assessor has less information than the one who made the claim assessed, this is not so: if I first claim that there cannot be a counterexample because I am in possession of a proof, and then later loose memory of, and access to, that proof, then it seems that I cannot correctly say that my earlier claim was wrong.

Finally Part IV comprises three papers that offer alternatives to relativism. Herman Cappelen approaches the issue from a particular point of view regarding the relationship between language use and semantics, namely speech-act pluralism, a view according to which the propositions asserted and communicated by an utterance are only quite loosely related with the proposition semantically expressed ("said") by that utterance. He argues that the data pattern usually presented in support of a relativistic semantics does not 
support such a semantics given this pluralistic view about the relationship between semantic content and speech-act content. He thus underlines the point I made in $\S 2$ (p. 6) above, that a semantic theory alone is not testable against any data pattern without some pragmatic assumptions, and shows how making certain pragmatic assumptions can render semantic relativism unnecessary.

In a similar way, Andrea Iacona argues that an alternative way to make sense of alleged cases of faultless disagreement about matters of taste is to distinguish between subjective and objective "readings" of the uses of predicates of personal taste. Where the sense is subjective, there is no disagreement, where the sense is objective, there is no faultlessness. The claim is not that taste predicates are systematically ambiguous, but rather that while the semantic content of these predicates is stable, there is variation in what we communicate with them.

Finally, Dan López de Sa explores a different alternative to relativism, namely indexical relativism. According to indexical relativism about taste, taste predicates are implicitly indexical. Accordingly, when you say "Homer is funny." and I say "He is not.", we may be expressing propositions that do not contradict one another, for example on one proposal you express the proposition that you find Homer funny, while I express the proposition that I find Homer funny. Thus there is no problem in understanding why neither of us need be wrong. However, the difficulty for indexical relativists is to explain the appearance of disagreement. López de Sa shows how we can explain this on the basis of a presupposition that we have a common sense of homour, thus answering one of the major problems for indexical relativism. 


\section{References}

Bach, Kent 2006: "Perspective on Possibilities: Contextualism, Relativism or What?". Paper presented at the Semantics \& Pragmatics Workshop Sheffield, 2 December 2006.

Borg, Emma 2004: Minimal Semantics, Oxford: Oxford University Press.

Cappelen, Herman and Ernie Lepore 2004: Insensitive Semantics. Oxford: Blackwell.

Carnap, Rudolf 1947: Meaning and Necessity, Chicago: Chicago University Press.

Carston, Robyn 2002: Thoughts and Utterances, Oxford: Blackwell.

Chalmers, David 2002: "On Sense and Intension". Philosophical Perspectives 16, pp. $135-82$.

—forthcoming: "Two-Dimensional Semantics", in Lepore and Smith (eds), The Oxford Handbook to the Philosophy of Language, Oxford: Oxford University Press.

Cohen, Stewart 1986: "Knowledge and Context". The Journal of Philosophy 83, pp. 574583.

DeRose, Keith 1991: “Epistemic possibilities”. Philosophical Review 100, pp. 581-605.

-1992: "Contextualism and Knowledge Attributions". Philosophy and Phenomenological Research 52, pp. 913-929.

Dreier, James 1990: "Internalism and Speaker Relativism". Ethics 101, pp. 6-26.

1999: "Transforming Expressivism". Nous 33, pp. 558-72.

Egan, Andy 2008: "Billboards, Bonds \& Shotgun Weddings". Forthcoming in Synthese. 
Egan, A., J. Hawthorne and B. Weatherson 2005: "Epistemic Modals in Context", in G. Preyer and G. Peter (eds), Contextualism in Philosophy, Oxford: OUP.

Einheuser, Iris this volume: "Three Forms of Truth-Relativism".

Evans, Gareth 1985: “Does Tense Logic Rest on a Mistake?", in his Collected Papers, Oxford: Clarendon Press, pp. 341-63.

Field, Hartry 1973: "Theory Change and the Indeterminacy of Reference". Journal of Philosophy 70, pp. 462-81.

Fine, Kit 1975. "Vagueness, Truth and Logic". Synthese 30, pp. 265-300.

Frege, Gottlob 1892: "Über Sinn und Bedeutung". Zeitschrift für Philosophie und philosophische Kritik 100, pp. 25-50. Reprinted in Günther Patzig (ed.), Funktion, Begriff, Bedeutung, Göttingen: Vandenhoeck \& Ruprecht 1986. English translation in McGuinness 1984.

_ 1918: "Der Gedanke. Eine Logische Untersuchung”. Beiträge zur Philosophie des deutschen Idealismus 1, 2, pp. 58-77. Reprinted in Günther Patzig (ed.), Logische Untersuchungen, Göttingen: Vandenhoeck \& Ruprecht 1986. English translation in McGuinness 1984.

[1915]: "Meine grundlegenden logischen Einsichten". Note published posthumously in Nachgelassene Schriften, edited by H. Hermes, F. Kambartel and F. Kaulbach, Hamburg: Felix Meiner 1983. English translation in Posthumous Writings, translated by P. Long and R. White, Oxford: Blackwell 1979, pp. 251-2.

Gibbard, Allan 1990: Wise Choices, Apt Feelings, Cambridge: Harvard University Press. 
Gillies, Anthony and Kai von Fintel 2006: "CIA leaks". Paper presented at Pacific APA meeting in Portland, 2006.

Harman, Gilbert 1975: “Moral Relativism Defended”. Philosophical Review 84, pp. 322.

Kaplan, David 1977/1989: "Demonstratives", in Almog et al. (eds.), Themes from Kaplan, Oxford: Clarendon Press 1989.

Kölbel, Max 2002: Truth Without Objectivity, London: Routledge.

_2003: "Faultless Disagreement". Proceedings of the Aristotelian Society 104, pp. $53-73$.

-2004: "Indexical Relativism vs Genuine Relativism”. International Journal of Philosophical Studies 12 (Oct. 2004), pp. 297-313.

2007: "How to Spell Out Genuine Relativism and How to Defend Indexical Relativism”. International Journal of Philosophical Studies 15, pp. 281-288. 2008: “The Evidence for Relativism”. Forthcoming in Synthese.

— forthcoming a: "Vagueness as Semantic", forthcoming in R. Dietz \& S. Moruzzi (eds), Cuts and Clouds: Issues in the Philosophy of Vagueness, Oxford: Oxford University Press.

— forthcoming b: "True' as Ambiguous". Forthcoming in Philosophy and Phemomenological Research.

Kompa, Nicola 2002: “The Context Sensitivity of Knowledge Ascriptions". Grazer Philosophische Studien 64, pp. 11-18. 
King, Geoffrey 2003: “Tense, Modality and Semantic Value”. Philosophical Perspectives 17, pp. $195-245$.

Lasersohn, Peter 2005: “Context Dependence, Disagreement, and Predicates of Personal Taste". Linguistics and Philosophy 28, pp. 643-86.

Lewis, David 1975: "Languages and Language", in Minnesota Studies in the Philosophy of Language 7, pp. 3-35. Reprinted in Lewis 1983.

1978: "Truth in Fiction". American Philosophical Quarterly 15, pp. 37-46. Reprinted in Lewis 1983.

1979a: “Attitudes De Dicto and De Se”. Philosophical Review 88, pp. 513-43. Reprinted in Lewis 1983.

1979b: "Scorekeeping in a Language Game”. Journal of Philosophical Logic 8, pp. 339-59. Reprinted in Lewis 1983.

-1980: "Index, Context, and Content", in Stig Kanger and Sven Öhman (eds.), Philosophy and Grammar, Dordrecht: Reidel. Reprinted in Lewis 1998.

1983: Philosophical Papers, Volume 1, Oxford: Oxford University Press.

1996: "Elusive Knowledge”, Australasian Journal of Philosophy 74: pp. 549-567.

1998: Papers in Philosophical Logic, Cambridge: Cambridge University Press.

MacFarlane, John 2003: "Future Contingents and Relative Truth". Philosophical Quarterly 53, pp. 321-36.

2005a: "Making Sense of Relative Truth". Proceedings of the Aristotelian Society 105, pp. 321-339. 
2005b: "The Assessment Sensitivity of Knowledge Attributions," forthcoming in Tamar Szabo Gendler and John Hawthorne (eds.), Oxford Studies in Epistemology 1, Oxford: Oxford University Press, pp.197-233.

2008: "Nonindexical Contextualism". Synthese.

— this volume: "Truth in the Garden of Forking Paths", in Max Kölbel and Manuel García-Carpintero (eds.), Relative Truth, Oxford: Oxford University Press.

_ forthcoming a: "Epistemic Modals are Assessment-Sensitive", in Brian Weatherson and Andy Egan (eds.), Epistemic Modals, Oxford: Oxford University Press.

forthcoming b: "Semantic Minimalism and Non-indexical Contextualism", forthcoming in G. Preyer and G. Peter (eds), Context-Sensitivity and Semantic Minimalism: Essays on Semantics and Pragmatics.

McDowell, John 1980: "Meaning, Communication and Knowledge", in Zak Van Straaten (ed.), Philosophical Subjects: Essays presented to P.F. Strawson, Oxford: Clarendon Press.

McGuinness, Brian 1984: Frege: Collected Papers on Mathematics, Logic and Philosophy, Oxford: Basil Blackwell.

Predelli, Stefano 1997: “Talk about Fiction”. Erkenntnis 46, pp. 69-77.

2005: Context: Meaning, Truth and the Use of Language, Oxford: OUP.

2006: "Operators on Contexts in the Semantics of Talk about Fiction", paper presented at Logic \& Language 2006 Birmingham.

Perry, John 1979: "The Problem of the Essential Indexical”. Nous 13, pp. 3-21. 
Price, Huw (1983) 'Does “probably” modify Sense?’. Australasian Journal of Philosophy 61: 396-408.

Prior, Arthur 1967: Past, Present and Future. Oxford: Clarendon Press.

Recanati, François 2004: Literal Meaning, Oxford: Clarendon Press.

_this volume: "Moderate Relativism".

Richard, Mark 2004: “Contextualism and Relativism”. Philosophical Studies 119, pp. 215-42.

Rysiew, Patrick 2007: "Epistemic Contextualism", The Stanford Encyclopedia of Philosophy (Fall 2007 Edition), Edward N. Zalta(ed.), forthcoming URL = $<$ http://plato.stanford.edu/archives/fall2007/entries/contextualism-epistemology/>.

Schlenker, Philippe 2003: "A Plea for Monsters". Linguistics \& Philosophy 26, pp. 29120.

Stalnaker, Robert 1987: Inquiry, Cambridge, Mass.: MIT Press.

2001: “On Considering a Possible World as Actual". Proceeding of the Aristotelian Society Supplementary Volumes 75, pp. 141-56.

Stanley, Jason 2000: “Context and Logical Form”. Linguistics \& Philosophy 23: pp. 391434.

Travis, Charles 1997: "Pragmatics", in Bob Hale and Crispin Wright (eds), A Companion to the Philosophy of Language, Oxford: Blackwell.

Wilson, Deirdre and Dan Sperber 2001: "Truthfulness and Relevance". Mind 111, pp. 583-632. 
Wright, Crispin 2001: “On Being in a Quandary”. Mind 110, pp. 45-98. Reprinted in C. Wright, Saving the Differences, Cambridge, Mass.: Harvard University Press 2003. 2006: "Realism, Relativism and Rhubarb", forthcoming in Greenough and Lynch (eds), Truth and Realism, Oxford: Oxford University Press.

Yourgrau, Palle 1983: “Knowledge and Relevant Alternatives”. Synthese 55, pp. 175190. 